\title{
Nigerian English in International Business Communication: Issues, Challenges and Prospects
}

\author{
Olushola Bamidele ARE \\ Department of English Studies, Adekunle Ajasin University, Akungba-Akoko, Nigeria \\ Email: areolusola@yahoo.co.uk
}

Received 27 March 2016; accepted 30 May 2016; published 2 June 2016

Copyright (C) 2016 by author and Scientific Research Publishing Inc.

This work is licensed under the Creative Commons Attribution International License (CC BY). http://creativecommons.org/licenses/by/4.0/

(c) (i) Open Access

\begin{abstract}
Effective communication is a crucial factor in business success in the global village that the world has come to be. In Nigeria, the overwhelming proportion of business with the outside world is conducted using the English. The need for Nigerian business people to use the language effectively will obviously contribute to success rates in their various interactions with business people from across the globe. However, as English becomes more domesticated in Nigeria, and as local varieties become more entrenched and less stigmatized, many Nigerians including those involved in international business may no longer be adequately conscious of the fact that the peculiar Nigerian ways they speak may pose fundamental communication challenges to non Nigerian business partners who may not be quite familiar with "Nigerian English". This paper explores these challenges by systematically aggregating findings from diverse practical observations of international business communication situations involving educated Nigerian. Based on some observed challenges, the paper advances some pedagogical innovations from the field of intercultural communication; to prepare Nigerian L2 English learners for enhanced oral communication performance in the international business world without having disparaging attitudes towards local varieties of English.
\end{abstract}

\section{Keywords}

Nigerian English, Intercultural Communication, Intelligibility, Business Discourse, Varieties

\section{Introduction}

One of the implications of the phenomenal global spread of the English language is the emergence of diverse 
non native (NN) varieties associated with societies where English is used as second language (L2). These countries, which Kachru (1992) referred to as outer circle countries in his concentric..., were largely colonized by the British and now use the language either as official language or language of education at one level or the other. Consequently, English in these countries has integrated into itself local coloration at all levels of language. This process is an inevitable outcome of a situation where a non indigenous language comes into a society and has to be used constantly by people with diverse cultures, languages and world views which are radically different from the culture and orientation of the original speakers of the non indigenous language. The departure from native speaker (NS) norms which this situation produces is the source of new varieties which are often referred to as new "Englishes".

Nigeria is one of the outer circle countries where a rich repertoire of peculiar usages have been gradually emerging over the years so much so that arguments are rife-albeit controversially-that a variety of English language has emerged. The variety serves the people who speak it efficiently, providing them with a means of "forcing" an imposed strange tongue to answer to their own linguistic whims and caprices. The question of how to place this variety has been a subject of lively debate among scholar but scholars like Selvi \& Yazan (2013) and Okunrinmeta (2014) have argued that Nigerian English (NE) and other non-native varieties should be recognized as a separate variety of English just like American English and Australian English. While the merits and demerits of argument do not fall within the scope of this paper, it is important to note that if this perspective ultimately gains upper hand, it will crucially impact upon the teaching and learning of English in Nigeria as it would determine whether NS norms would continue or cease to be the reference point for teaching both oral and written components of the language.

While the academic arguments and discussions rage on, the variant features of English as it is generally used in Nigeria continue to wax stronger as the English language gains more ground in the society, replacing local languages in many situations that were their exclusive preserves some years ago. Indeed, in many homes, English has now become the language of communication. As Are (2010) opines, there are now many young persons who either learn to speak the Nigerian version of English before attempting to learn a local language or learn English alongside their local languages. The English that is acquired in a non instructional environment in Nigeria obviously cannot follow NS norms. This trend has further entrenched norms that emerged locally. Coupled with this, the collapse of the educational system and the attendant injection of low quality teachers into the system have created a situation where the schools are no longer able to inculcate the NS norms which the examination bodies still favour.

One of the reasons why English continues to be favoured as official language in Nigeria is the fact that it has the capacity to serve as a language of international communication. To serve this purpose adequately, the English spoken by Nigerians must be considerably internationally intelligible. There is however a possibility that the imperative of international intelligibility is being progressively compromised by the rise and rise of the peculiar Nigerian variety of English, as the variety clearly contains features that can confuse many speakers of English who are not Nigerian and who are not familiar with Nigerians.

As economic interactions between societies increase in the global village the world has become, the challenge of international intelligibility will become more and more relevant in academic appraisals of several Englishes that have emerged and continue to evolve. In the case of Nigeria, a considerable array of peculiar commerce related usages has been identified (Gut, 2012).

The potential of these to considerably affect business interactions between Nigerians and foreign business partners is assessed in this article. To enhance this assessment, the article provides an overview of the concept of Nigerian English, providing insights into the uniqueness of its segmental features as well as discourse and pragmatic elements. It also assesses the crucial matter of international intelligibility as it relates specifically to international business atmospheres. The article thereafter provides an overview of the nature of international business involvements of Nigerians and offers some recommendations for enhancing efficiency in international business communication, in spite of the potential communication challenges that may be attendant to the emergence of the "new" English, with emphasis on oral language.

The recommendations herein are considerably informed by the cultural criticality approach to the study of intercultural communication. In view of this, an overview of the concept is presented.

\section{Nigerians and International Business Transactions}

The media is awash with negative information about Nigeria with regard to corruption, terrorism, financial 
scams and so on. Indeed, the country has underperformed socially, politically and economically. It suffers from what Sachs and Warner (2001) cited in Arodoye and Iyoha (2014) referred to as the "natural resource curse" which is a "systematic tendency for narrowly specialized primary commodity exporters to grow more slowly than countries with more diversified exports." As a consequence of this, the country has oscillated within the vicious boom and bust cycles generated by the volatility of world oil export prices. Income from oil exports were not effectively used to achieve economic development due to extreme corruption, particularly under the military dictatorships between 1966 and 1999. Above all, serious miscalculations occurred in macroeconomic policies. In spite of these, the country has in recent times maintained modest albeit inconsistent growth rates ranging from 5.1\% in 2011 to 7.4\% in 2013 (Emefiele, 2014), and the current 5.94\% - 6.00\%, as indicated on tradingeconomics.com.

Arodoye and Iyoha (2014) observe that there is always a positive relationship between foreign trade and economic growth. In this regard the modest growth, which of course has had little impact on real development and the Nigerian masses' quality of life, can be linked to some modest measure of international trading activities. Many foreign companies from different parts of the world conduct business in Nigeria especially in the import and export sectors. For the purpose of this paper, it is important to note that most of these countries are not English speaking countries. Available figures from the National Bureau of Statistics for the fourth quarter of 2014 indicate that among the top ten nations Nigerians traded with only three-United Kingdom, South Africa and the United States-were English speaking countries, representing less than $40 \%$ of total export trade. Among the top ten nations Nigerian imported from during the same period, only the USA and the UK were English speaking countries, representing less than $30 \%$ of import trade.

The implication of the above is that although Nigerians' business interactions with the outside world mainly involve the English language, most of the people they interact with are often not NS users of English.

\section{Perspectives on Intercultural Communication: The Cultural Criticality Approach}

When people have to communicate across culture, issues are bound to emerge, and such issues would have to be factored into communicative strategies. This is the focus of studies in cross cultural communication. The term is used to describe communication processes and problems that occur in different contexts where people from different cultural backgrounds interact. It focuses on the understanding and misunderstanding, the agreement and disagreement, the conflict and cooperation, and so on.

One of the principal focal points of intercultural communication studies is language. This is because language is the principal mode of transmission of culture. However, language is just part of the mix which includes beliefs, social attributes, thought patterns and so on. Indeed, culture itself is a pattern of learned, group related behaviour including both language and other means of communication, attitudes, values, beliefs and conventions that have come to characterize a group of people. The factor of language in this description is crucial. This paper views issues in intercultural communication as issues of direct relevance in studying NE and its intelligibility in non Nigerian context as many of the attributes of NE emerged from and continue to emerge from the cultural uniqueness of the peoples of Nigeria.

There are different approaches to the study of intercultural communication, especially the dimension that has to do with pedagogical processes that can prepare learners for intercultural communication. In this regard, Humphrey (2002) describes intercultural communication as a new objective in modern language learning and teaching. This is an objective that requires its own pedagogical methods and principles. Humphrey reviews a number of approaches to the incorporation of this new learning objective into language teaching programmes. These approaches are selected based on a number of criteria which Humphrey considers salient. The approaches include: the cultural criticality approach, the dynamic, process approach, the "emic" and "etic" approach, and experiential learning circle approach.

The cultural criticality approach involves attempts to isolate the significant cultural differences between peoples, respect them, and study how to negotiate the communicative barriers they create. The dynamic, process approach on the other hand involves the identification and analyses of a broad range of cultural practices and meaning systems, based on a focus on their changing patterns. The emic and etic approach involve either studying a cultural context from within (emic) or from without (etic), based on the use of set criteria as standard. Finally, the experiential learning circle approach emphasizes learning how to communicate in a new context via 
practical experiences of that culture.

The cultural criticality model seems amenable to adaptation for the purpose of this work. Not all aspects of NE usages are culturally based, and not all situations of communicative barriers are culturally based. Phonological and morpho-syntactic deviations from NS norms are, for example, not based on culture. However, pragmatic and discourse features as well as lexico-semantic elements are critically centered on cultural dynamics. In any case a sound grounding in intercultural communicative skill provides a psychological disposition of preparedness for "linguistic eventualities" that may arise even from the use of pronunciation patterns that deviate from NS standards.

The cultural criticality model appears to be useful as basis for pedagogical approaches that will highlight to language learners, the cultural, pragmatic, discourse, and lexico-semantic and non verbal variables that impinge heavily on the success or otherwise of interpersonal communication, especially in the context of international business. This will be explored in this paper.

\section{The Concept of Nigerian English: An Overview}

Nigerians have undoubtedly forced the English language to serve new masters. They have pummeled it to submit to their own social, political and psycholinguistic realities. Decades ago, scholars began to recognize the phenomenon. To this day, the ensuing academic discussions are ongoing. As previously stated in this paper, big question remains regarding whether the peculiar features of English in Nigeria are sufficient and properly codified enough to be identified as a variety. Adegbite (2012: p. 39) summarizes these controversies beautifully:

We all know there is such a thing as British English, as the progenitor of all subsequent "Englishes" in the world. And we do, of course, know that there is American English,.... What is Nigerian English? Is there a thing as Nigerian English? If there is, how is it different from or similar to British English and American English?

This controversy has existed for a long time and would continue for a long time in spite of some modest codification efforts. Going into this debate could create a distraction from the focus of this article. The term NE is therefore simply used here, as a referent to those obvious deviations from NS norms that are peculiar to Nigerian speakers of English regardless of whether a well defined and codified system is identifiable or not.

Nigeria is considered to be one of the important countries among the post colonial societies where new varieties of English have emerged. The reason for this is the shear size of the population of English speakers. Graddol (1997) cited in Adegbite (2014) estimated that there are about 43million speakers of English in Nigeria. This is to be expected because English is an official language in the country, which has an estimated population of 160million. The status of English as the dominant official language, makes it the language of administration, education, the mass media, business transactions, politics, judicial procedure, science, and international communication. The language also serves as vehicular language, providing a linguistic bridge in a country where hundreds of mutually unintelligible indigenous languages exist side by side.

In this situation, the variety that has emerged has a number of regionally and educationally based sub-varieties which either operate along geographical, social, psycholinguistic and educational parameters as variously described in scholarly work such as Odumuh (1987), Adegbija (1989), Adedeji (2007), Akindele \& Adegbite (1999).

Notable among the variety classification done by scholars in the past is the early but still influential one by Banjo (1971). This classification is based on linguistic and sociolinguistic parameters as well as international intelligibility and social acceptability. Four varieties of the

Spoken English of Nigerian are identified. Variety 1 is characterized by transfer of phonological, syntactic and lexical features of mother tongue to English language. This variety lacks social acceptability and international intelligibility. Variety 2 is more similar to Standard British English in syntax but not phonologically and lexically. It is socially acceptable, but has limited international intelligibility. Variety 3 also shares the features of Standard British English in syntax, semantics, and phonology. It however has unique phonetic and lexical elements. Social acceptability and international intelligibility are high. Variety 4 is almost like British English, and is consequently socially unacceptable though internationally intelligible. Of course, variety 3 is recommended by the scholar as the better candidate for adoption as national variety.

While this, as indicated above is just one out of the many perspectives that exists in the literature on NE, there is a key concept raised in the work which deserves close attention. This key concept is the concept of international intelligibility. This concept, used as a criteria in discussing standardization issues in Nigerian English, 
suggests that the need for an acceptable variety of English language to continue to serve the function of providing a linguistic bridge to the outside world. Obviously, this is as important as the criterion of local social acceptability is crucial.

\section{Features of Nigerian English}

Features of NE features cut across all levels of language analysis including the supra segmental level. There are several examples, many of which are identified in Odumuh (1987), Adegbija (1989) and Adedeji (2007) among other publications. These include discourse and pragmatic features arising from cultural transfers from Nigerian languages, phonetic features such as stress misplacement, sound substitution, the tendency to match pronunciation with orthography as well as the tendency to ignore the intonational aspects of BE. It is important to note that the phonetic issues are crucial because they produce accent which are immediately noticeable to many non-Nigerians, especially when these non-Nigerians find them confusing. They are significant in the intelligibility challenges of NE.

There are also a number of morpho-syntactic features such as the pluralisation of words not normally pluralized in $\mathrm{BE}$, the omission of articles and the unique use of preposition resulting in phrasal verbs such as "discuss about" and "emphasize on". Morpho-syntactic features also include the peculiar use of the progressive form to produce expressions such as: "I am understanding you" and "I am seeing you". In addition, some words are often used as word classes they are not normally associated with in British English. For example "horn" can be used as a verb in a sentence like "Please horn before over-taking".

Lexico-semantic features perhaps account for the bulk of NE unique elements and sometimes pose extreme intelligibility challenges. Meaning is often transferred from the local culture and context, and sometimes, semantic shifts and generalizations (involving the restriction or narrowing of the semantic range of words) occur. Also, coinages and neologisms abound as well as the hybridization of the English and indigenous word.

\section{The Intelligibility Issue}

For domestic functions, serious issues of communication breakdown have not been reported in any research in spite of the existence of regionally or ethnically based variations in usage. For external communication however, one may naturally assume that there may be need for concern. However, many of the advocates of standard NE have often claimed that it is internationally intelligible (Banjo, 1971; Bamgbose, 1982; Adegbite, 2014). This is something that requires some deep consideration considering the fact that it has still not received enough attention via scientific research.

Unfortunately, an old research reported in Tiffen (1974) remains one of the few detailed field research-based reports on a scientific investigation of the intelligibility of NE. It was based on a study conducted among university students who are among the groups usually associated with English spoken by tertiary level educated Nigerians and considered as benchmark for determining what the "standard" should be among the various regional and educational-level-based varieties of English in Nigeria (Banjo, 1971). The outcome of the investigation revealed that averagely, speakers of NE were $65 \%$ as "efficient" as British speakers of Received Pronunciation (RP). There was a minority of persons whose speech form was $93 \%$ as efficient as the British speakers who spoke in RP. On the other end there was a group of the least intelligible Nigerian speakers whose speech form was $30 \%$ as efficient as the RP speakers.

If the average intelligibility rate was 65\%, educated NE would appear to cross a pass mark of international intelligibility. Yet, the extent of intelligibility failures discovered in this research are still important, especially when one considers the impact which intelligibility failures can have on formal communication contexts such as international business communication contexts. Talbot (2009) explains that in the business world, when people get merely puzzled by the communication of others there can be adverse effects on results, and "getting the right messages out and receiving the right answers are the life blood of commercial success" (p. 10). It is worthy of note that she advocates that the panacea for this possibility is to ensure that in intercultural settings, participants in the communication context use "commonly accepted standard English." Although the idea of an accepted standard is problematic, the possibility of communication failure as a result of the use of unfamiliar variety of the language cannot be ignored.

Tiffen (1974) identified aspects of NE that were responsible for intelligibility failures. Since the identified features still occur today, they remain relevant. These features were categorized into four groupings, which are 
rhythmic/stress, segmental, phonotactic, lexical/syntactic. Tiffen noted the fact that rhythmic/stress errors committed by $38.2 \%$ of all speakers were the major cause of intelligibility failure, closely followed by segmental errors which accounted for $33.0 \%$. Phonotactic errors accounted for $20.0 \%$, while lexical/syntactic errors (8.8\%) were relatively insignificant.

Thirty nine years after Tiffen's research, NE has become more entrenched and more unique, raising the need for research into the current intelligibility situation.

Apart from intelligibility, there are related issues of attitudes to accented speech or non native English. Flege (2002) observed that accented samples of speech are "consistently rated less favorably on scales ranging from kind-cruel or intelligent-stupid". This, the scholar observes, combines with the reality that, foreign accented speech is "typically less intelligible than the unaccented speech of native speakers".

The bottom line of the discussion of the above is that the intelligibility question remains relevant, requiring continuing inquiry. This is why this research considers how the intelligibility issues arising from the use of NE impinge upon international business communication involving Nigerians.

\section{Methodology}

The study is meant to investigate how the peculiarities of NE affect the international business transactions of Nigerians in view of the challenges associated with intelligibility issues. The general population for this research consists primarily of educated Nigerians, who engage in constant business contacts with non Nigerians from outside Africa. In order to gain practical insight into the realities of international business communication involving the category of people described above, this researcher decided that it would be helpful to interview Nigerians who have for many years worked in the context of international business and are able to discuss their personal experiences and the experiences of other Nigerians with whom they have worked in international business environments for years. This researcher decided to involve a manageable number of persons who have thorough understanding of the issues involved in the research, as they would not merely be research respondents but also research agents who would function as the eyes and ears of the researcher in the communicative contexts being investigated. Whatever they reported during the interview sessions represented aggregations of their own personal communicative experiences and those of several other Nigerians. 10 individuals were selected for this exercise. This included a top female executive of an IT company who worked for several years in Nigeria and now lives in the USA, a female translator from Nigeria who lives and works in Belgium and specializes in translating for Nigerian visitors to Belgium, a male Nigerian trader who shuttles between UK and Nigeria, a female Nigerian company executive who works in the UK and a male public service consultant in the UK. The list also included a Nigerian proprietor of a travel agency with offices in Nigeria and Germany, a Nigerian male shipping agent based in Canada, three Nigerian male international traders based in Lagos. All the interviewees were tertiary level educated persons. Obviously, the selection of the recruited observers was purposively done based on researcher assessment of their suitability.

Having established that research agents had clear understanding of the issues involved in the research, interviews were conducted based strictly on unstructured open ended question. This meant that the specific questions asked depended on a number of factors including the mood of the respondent, how patient they were, the level of knowledge the respondent displayed, and the quality or adequacy of the responses they provided for each question.

In spite of the open ended nature of the interview, there was a measure of consistency in the general flow of the interview. The dominant issues centered on:

1) Finding out how aware educated Nigerians are of the unique aspects of the English they speak.

2) Finding out the communication problem these Nigerians encounter, especially in business contexts.

3) Finding out the practical implications of such problems for business transactions.

4) Identifying the way Nigerians attempt to respond to or solve the communication problems they encounter.

5) Finding out the effects of the usual attempts of many Nigerians to enhance intelligibility by trying to force a change in their accent.

6) Asking the respondents to recommend, based on their practical observation/experiences, the best strategies that could enhance communication effectiveness in spite of the use of NE

From the above, it is obvious that the focus (as indicated earlier) is on oral communication because this is where the problems are predominantly manifest. Although there are some peculiar Nigerian usages in written 
English, written English does not seem to be as adversely affected by problems with varieties as oral language. Generally, uniformity in style in written English language is still significantly higher compared to speech (Talbot, 2009).

Subsequently, qualitative summations of the responses of the interviewees are presented as the findings. They are listed in accordance with the general areas of interview focus (listed above) which are treated as operational research questions in this paper. The findings are thereafter discussed.

\section{Findings}

\subsection{Awareness of Nigerian English}

8 out of 10 of the research agents interviewed gave answers indicative of the fact that the Nigerians they have observed, though conscious of accent differences, appear neither to have enough prior awareness of the extent of the uniqueness of the varieties of English they speak nor prior awareness that it could potentially constitute a barrier to effective communication in English with non Nigerians. One interviewee suggested that Nigerians he had observed were more concerned about or amused by the accents of non-native English speakers than their own. Consequently they are not quite prepared for the challenges they find themselves encountering.

\subsection{Communications Problems Encountered}

9 out of 10 of the research agents claimed they have observed that some Nigerians who find themselves in international contexts are often faced with communication hitches they are not prepared for, such that they often have to struggle to be understood, and also struggle to understand others. The categories of people observed by the research agents were educated to secondary school level and above (most had tertiary education), and probably speak the varieties that have been sometimes touted as "standard" NE which is said to have international intelligibility in line with the views of Banjo (1971). This suggests that the so called educated NE does have profound problems of international intelligibility. Interviewees opine that Nigerians tend to adjust their discourse strategies and often switch to the use of more intelligible English within short periods of constant exposure to conversation with non Nigerians.

\subsection{Practical Implications for Business}

The implications vary depending of the nationality of the other parties in the conversation context. 8 out of 10 respondents claim that that they observe some measure of prejudice and impatience, leading to loss of confidence on the part of the Nigerian, especially when native speakers of English are involved. With non native speakers of English, the situation is often less problematic such that no serious issues of prejudice are reported in interactive discourse situations.

\subsection{Responses to Communication Challenges}

All the research agents observed the tendency to try to force a change of accent in order to be understood. Other strategies include speaking slowly and engaging in constant repetition.

\subsection{Effects of Forced Accent Change}

Only one agent claimed to observe positive outcome in the form of enhanced intelligibility when speakers recourse to forcing accent changes. Other respondents are of the opinion that this may sound like a charade and cause the other participants in the conversation to have an attitude of subtle derision. (A particular interviewee made the curious claim that this puts the Nigerian in a weak negotiating position in some situations).

\subsection{Communication Strategies That Work}

The agents all point out the need to make some adjustment in order to overcome the barrier posed by using NE in international business contexts. In other words, to achieve better communication and better impact in business, using English strictly the way it comes naturally may not be advisable for a Nigerian especially in dealing with NS users of English. Specific strategies that are observed to work include: slowing down the pace of speech and learning some new ways of expressing ideas. The respondents observed that it was important to override the 
problems associated with the use of a NON NATIVE variety of English with proper marshalling of points and facts, bolstered by a conscious effort to resist being intimidated. In this regard 5 out of ten respondents, recommend that forced accent change should be avoided as it could signal weakness during tough negotiation session.

\section{Implications of Findings}

One of the important elements of success in formal communication situations especially in intercultural context is the possession of "effective intercultural communication skill" (Humphrey, 2002). This element is compromised when for one reason or the other a person is unprepared for intercultural communication, so much so that the person experiences linguistic/culture shock when confronted with intercultural communication situations. In the situation of speakers of NE, effective intercultural skills would involve adequate awareness of the possible intelligibility challenges that may occur when NE is used in communication contexts in which some participants are non Nigerians. From the findings itemized above, it is clear that there is a deficiency in this regard, leading to several hitches and in some cases failure of business transaction.

There are a number of very serious issues that emerge from this. First, the claims that educated NE (which is often touted as the potential "standard NE") is internationally intelligible, has to be scrutinized very closely. One may recall that in a previous section in this paper, it is clearly stated that most of the persons observed by the research agents used in this research are tertiary level educated. Yet, the consensus observations recorded for this research indicated that there are profound problems. Secondly, it is important to understand that business contexts are particularly sensitive. One may not subscribe to the insistence of Talbot (2009) on the use of "commonly accepted standard English" as the panacea for effective communication in international business context. Also, it seems unnecessary to heed the call in Adedeji (2007) for standards to "gravitate towards the Anglo-American standard if at all Nigerians will be intelligible to the rest of the world.” This simply is not in line with the natural dynamics of language. Yet, it is important that speakers of NE should be prepared for intercultural context where many of the culturally based deviations from NS norms may present serious challenges.

Although speakers of NE often succeed in improvising ways of getting around the problems they encounter (as reported in the findings above); and the research agents are able to identify some strategies that actually work, one point must be noted: the initial shock which one way or the other, limits the communicative capacity of the concerned person, albeit temporarily in some individual, can be avoided via adequate preparation that could be incorporated into pedagogical practices. This is what (Kramsch, 1981) referred to as "discourse preparedness.” The objective of such a pedagogical approach would be to limit the occurrences of criticality incidents when the learners find themselves faced with situations that require rapid linguistic adjustments.

The importance of discourse preparedness is underscored by one of the responses to criticality incidents suggested by the research agents used in this research; that is the imperative of overriding communicative hitches engendered by the use of an English variety the listener struggles with, by maintaining confidence and ensuring competence in the quality of the message, especially in formal business discourse. Strategies such as these are crucial in beating the barriers of prejudice.

It also emerged from this research that there are essential differences between the ways native speakers respond to NN varieties and the ways NN speakers respond. Also, it emerged that attempts to force-change accent may in some cases be quite counter productive. The tendency of speakers of NE to recourse to excessive use of non verbal communication is a crucial issue. These kinds of details (and most likely many more that are not captured in this research) need to be incorporated into L2 instruction, bearing in mind the increasing need to use English language as an international language.

As things are now, there is absolutely no aspect of any English language curriculum used in Nigeria that contains elements that can inculcate intercultural communicative skills. There are teaching objectives that seek to eliminate problematic aspects of spoken English in the hope of achieving international intelligibility. These measures (obviously) hardly succeed.

There is increasing local acceptability of NE as reflected in a work like Okunrinmeta (2014), and the increasing international tolerance of NN varieties among English instructors as reflected in Selvi \& Yazan (2013). While these are positive developments, they bring to mind the imperative of balancing acceptance with functionality. Therefore, there remains a need to sensitize learners to the hard reality of potential problems in intercultural communication contexts. 
One must however concede the fact that this is a study limited by a small sample size. In this regard, there is room for further research towards the confirmation of these findings, and to keep abreast of the dynamic of NE in international contexts as they unfold.

\section{Conclusions and Recommendations}

Going by the outcome of this limited research, the situation of speakers of NE in international business contexts is not completely precarious in spite of the areas of difficulty identified. This is because they are often able to adjust to these difficulties by the use of specific improvised discourse strategies. However, it is important to note that the initial shock they sometimes encounter and the attendant failures, especially in transactional and performance discourse contexts (such as business situations), could be prevented with adequate discourse preparedness in the context of intercultural communication. It is for this reason that the broad principles of the cultural criticality approach to intercultural communications are favoured in this paper.

It is perhaps important to reiterate the fact that not all aspects of NE are culturally based. The point is that a holistic and global inculcation of awareness of divergences in cultural and communicative values, mixed with awareness of the uniqueness of $\mathrm{NE}$ and the potential areas of difficulties in international use, can be very helpful to Nigerians. In this regard, a number of recommendations are made.

1) In teaching English in Nigeria, and perhaps in other outer circle societies, the teaching programmes should include elements of English as an International language (EIL), such that discourse and pragmatic differences across cultures, as well as segmental differences in English usage across culture are highlighted. Discourse strategies that would enable learners to negotiate the complex barriers created by differences should be emphasized to enhance discourse preparedness.

2) The emphasis of such teaching programmes should be on transactional and performance discourse contexts, as these appear to be more problematic than interactional discourse. Such a focus will enhance business communication success, especially where negotiations and presentations are involved.

3) The view that only Anglo-American varieties should be upheld appears to have little foundation in view of the fact that those who speak these varieties are in minority in the English speaking world today (Selvi \& Yazan, 2013). In any case, the bulk of foreign business interactions involving Nigerians do not involve NS English (as earlier mentioned). Therefore, while the existing dogmas about standard may remain in use among Nigerian examination bodies, intercultural communication elements can be introduced.

It is also important to encourage business people involved in or planning to be involved in business with Nigerians to take advantage of the existing opportunities to get familiar with NE. Fortunately, the International Corpus of English project, which is freely available online, now has a NE component available at http://sourceforge.net/projects/ice-nigeria/. It covers a wide range of peculiar Nigerian usages in both written and oral English, including words and expressions used in business transactions. An overview of this great step towards the codification of NE is made in Gut (2012).

\section{References}

Adedeji, M. (2007). Linguistic Features of Nigerian English. The 24th Annual Conference of the Nigeria English Studies Association (NESA) held at the CBN Auditorium, University of Uyo, Akwa Ibom State, 18-21 September 2007.

Adegbija, E. (1989). Lexico-Semantic Variation in Nigerian English. World Englishes, 8, 165-177. http://dx.doi.org/10.1111/j.1467-971X.1989.tb00652.x

Adegbite, W. (2012). Methodology in the Codification of Nigerian English. JNESA, 15, 39-45.

Adegbite, W. (2014). Thoughts on a Dictionary of Nigerian English Usage: A Step in the Codification of Nigerian English. Akungba-Akoko: The Faculty of Arts Seminar, Adekunle Ajasin University.

Akindele \& Adegbite. (1999). The Sociology and Politics of English Language in Nigeria. Ife: Obafemi Awolowo University press.

Are, O. B. (2010). Relationships between Reading Competence and Interest in Reading in the Nigerian ESL Context. Unpublished Ph.D. Thesis, Abuja: University of Abuja.

Arodoye, N. L., \& Iyoha, M. (2014). Foreign Trade-Economic Growth Nexus: Evidence from Nigeria. CBN Journal of Applied Statistics, 5, 121-140.

Bamgbose, A. (1982). Standard Nigerian English: Issues of Identification. In B. B. Kachru (Ed.), The Other Tongue: English across Cultures (pp. 95-111). Illinois: University of Illinois Press. 
Banjo, A. (1971). Towards a Definition of Standard Spoken Nigerian English. Annales de Universite d'Abijan, 24-28.

Emefiele, G. (2014) Entrenching Macro-Economic Stability and Engendering Economic Development in Nigeria. Text of an Address by the Nigerian Central Bank Governor during His Maiden Press Briefing. http://www.cenbank.org/OUT/2014/CCD/GOV\%20\%20EMEFIELE\%27S\%20VISION\%20PAPERJUNE\%202014.PDF

Flege, J. E. (2002). Factors Affecting the Pronunciation of a Second Language. http://jimflege.com/files/Colorado_2002.pdf Gut, U. (2012). Toward a Codification of Nigerian English: The ICE Project. JNESA, 15, 1-13.

Humphrey, D. (2002). Intercultural Communication: A Teaching and Learning Framework. https://www.llas.ac.uk/resources/paper/1303

Kramsch, J. C. (1981). Discourse Analysis and Second Language Teaching. Washington, DC: Center for Applied Linguistics.

Odumuh, E. (1987). Nigerian English. Zaria: Ahmadu Bello University.

Okunrinmeta, U. (2014). Syntactic and Lexico-Semantic Variations in Nigerian English: Implications and Challenges in the ESL Classroom. Open Journal of Modern Linguistics, 4, 317-332. http://dx.doi.org/10.4236/ojml.2014.42026

Selvi, A. F., \& Yazan, B. (2013). Teaching English as an International Language. Alexandria: TESOL International Association.

Talbot, F. (2009). How to Write Effective Business English. London: Kogan Page Ltd.

Tiffen, B. W. (1974). The Intelligibility of Nigerian English. Ph.D. Thesis, London: University of London. 